American Journal of Applied Sciences 9 (3): 429-435, 2012

ISSN 1546-9239

(C) 2012 Science Publications

\title{
The Computational Fluid Dynamic Simulation of Fire Evacuation from the Student Dormitory
}

\author{
${ }^{1}$ Teeranon Saelao and ${ }^{2}$ Supat Patvichaichod \\ ${ }^{1}$ Department of Mechanical Engineering, \\ Faculty of Engineering, Kasetsart University, Thailand \\ ${ }^{2}$ Department of Mechanical Engineering, Faculty of Engineering at Si Racha, \\ Kasetsart University, Si Racha Campus, Thailand
}

\begin{abstract}
Problem statement: The aim of this research is to investigate the fire evacuation problem from the student dormitory by using the Numerical method. The Fire Dynamics Simulator Software was used in the research with the evacuation function (FDS + Evac.). The problem under investigation concerns the building that has the open-air centre. The characteristics of the building are included with 5 floors, 2 open-air fire escape stairs located at 2 sides of the building. In addition, there is a single exit to the outside of the building and the sprinkler system is not installed inside the building. Approach: The simulation was designed to study the problem that has a source of fire occurring at the room closed to the open-air stair. The stairs will be severely affected by the smoke. The experimentation's are composed of 4 cases, which are (1) the first case assumes the true size of the door is $1 \mathrm{~m} \mathrm{(2)} \mathrm{the} \mathrm{second}$ case assumes the true size of the door is $1 \mathrm{~m}$ and the smoke barrier is installed at the beam located before the stair entrance (3) the third case assumes the true size of the door is $2 \mathrm{~m}$ and (4) the fourth case assumes the true size of the door is $2 \mathrm{~m}$ and the smoke barrier is installed. Results: The results are shown that the escape time from the building with the $1 \mathrm{~m}$ door is $465 \mathrm{sec}$ and the $2 \mathrm{~m}$ door is $265 \mathrm{sec}$. The time differentiation between the $1 \mathrm{~m}$ door and the $2 \mathrm{~m}$ door is $200 \mathrm{sec}$. The reason is the waiting occurred at the entrance if the smoke barrier is not installed. In this case, the smoke in the stairs without a smoke barrier installation has more than the smoke in case if the smoke barrier is installed. However, this research collected the data of the gas volume and found that the gas volume is not yet harmful to human life but the gas can be an obstacle to evacuation in the building that has an open-air centre. Conclusion: For safety reasons, the building's user should improve the door size and install the smoke barrier at 2 sides of the stairs for all floors to increase the evacuation ability.
\end{abstract}

Key words: Fire evacuation, fire dynamics simulator, numerical simulation, student dormitory, evacuation time, Fraction Effective Dose (FED)

\section{INTRODUCTION}

The fire evacuation is a necessary activity when the severe situations are occurred, for examples, the earthquake, the gas leaks, the hostage and the explosion. The escape time depends on various criteria, which are the characteristics of the building's user, the characteristics of the building itself and the layout design in the building. Even though the building is well designed, the activities such as the efficiency and the ability of fire evacuation have to be tested and measured.

Explained the equation of escape time $\left(\mathrm{T}_{\text {escape }}\right)$ as shown in Eq. 1 in which the 3 components are included:

$\mathrm{T}_{\text {escape }}=\mathrm{T}_{\mathrm{p}}+\mathrm{T}_{\mathrm{a}}+\mathrm{T}_{\mathrm{rs}}$
Where:

$\mathrm{T}_{\mathrm{p}}=$ The perception time to fire situation

$\mathrm{T}_{\mathrm{a}}=$ The action time to fire situation

$\mathrm{T}_{\mathrm{rs}}=$ The travel time to a safe place

The evacuation simulation software has an ability to calculate an escape time. The start time and the action time of evacuation to provide the user's perception of evacuation time is also included in the software. In addition, other factors that relating to the travel time are included in the software, which are the population size, the evacuation speed, the density of people, the door width, the evacuation route, the distance to the safe place, the building shape, the behavior and the familiar to the place and the toxic volume that are increased in the combustion process

Corresponding Author: Supat Patvichaichod, Department of Mechanical Engineering, Faculty of Engineering at Si Racha, Kasetsart University, Si Racha Campus, Thailand 
from decoration materials in the building. However, the software is limited to calculate the action time and the perception time. Using evacuation simulation software is recommended to be a choice to investigate either potentials or flaws of the evacuation area. Time and cost can be saved in case of the evacuation plan is implemented. A lot of researchers contributed to the evacuation and numerical simulation such as, $\mathrm{Ma}$ and Quintiere (2003); Xin et al. (2005). Zhang et al. (2007); Lin and Chuah (2008); Roh et al. (2009); Qin et al. (2009); Mouilleau and Champassith (2009); Merry et al. (2009); Zahim et al. (2009); Momani (2010); Majee and Roy (2010); Yang et al. (2011); ZhiXiang et al. (2011) and Jahn et al. (2011).

\section{MATERIALS AND METHODS}

Building characteristics: The student dormitory characteristics in this research are a building with 5 floors, 2 stairs leading to the ground floor and open-air center. There are 120 rooms in which 4 students can live in a single room. Total number of students in the dormitory is 480 persons. There is only a single exit to the outside of the building, where is located in the left hand side with $1 \mathrm{~m}$ width. The problem is designed in that the source of fire is located at the first floor in a room closed to the fire stair. The objective of the study is to evaluate the risks of student's evacuation during moving in the stair passage. The stair characteristics are opened area in which smoke can leak to the stair passage. The building characteristics are shown in Fig. 1-3, whereas the Fig. 1 shows the left hand side view of student dormitory, Fig. 2 shows the inner area of student dormitory and Fig. 3 shows the inner area of the student dormitory of 2nd-5th floor.

Location of source of fire: The risk evaluation is a process that is required to select the location of the most severe source of fire, especially the location that affects to the evacuation and to the life of evacuating people. Because the open-air stair increases the risk of smoke moving to the stair passage, so the location of the source of fire is set closed to the left hade side of the stair passage of the first floor as shown on Fig. 4.

The size of fire used in the simulation model is selected by the type of polyurethane, which are almost used as a material in the building. To determine the heat release rate referred from Table 1, if the heat energy is $7,000 \mathrm{~kW}$ with the fire area of $1 \mathrm{~m}$, heat release rate per area is $7,000 \mathrm{~kW} \mathrm{~m}^{-1}$.

The factors using to consider the fire situation in this research that the evacuating people can endure with the fire in a short time of evacuation are referred as printed in "the NFPA 130 Standard for Fixed Guideway Transit and Passenger Rail Systems". The factors are composed of the air temperature and $\mathrm{CO}_{2}$ volume. The values by the standard are shown in Table 2 and 3 .

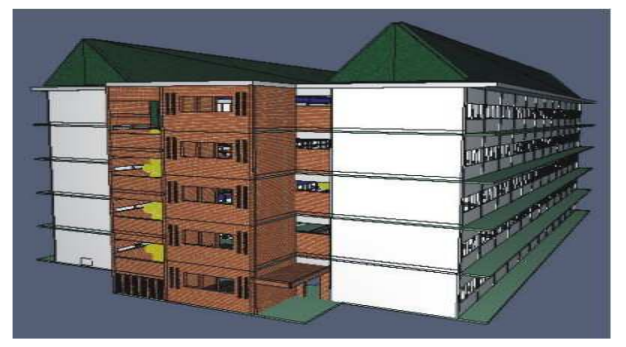

Fig. 1: Depicts the left hand side view of the student dormitory

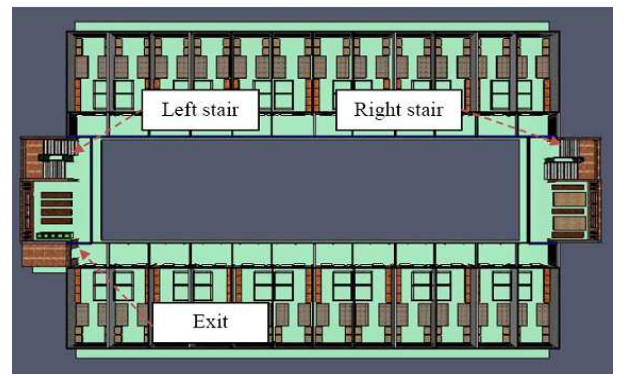

Fig. 2: Depicts the inner area of the student dormitory

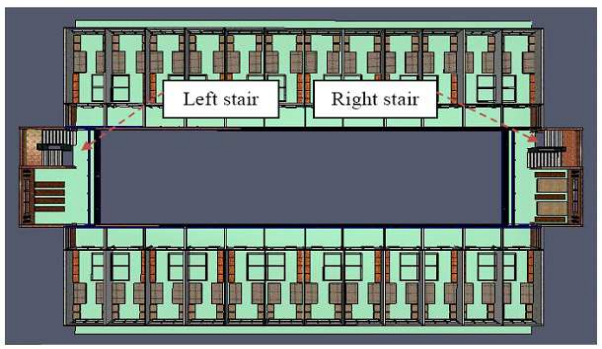

Fig. 3: Depicts the inner area of the student dormitory of 2nd-5th floor

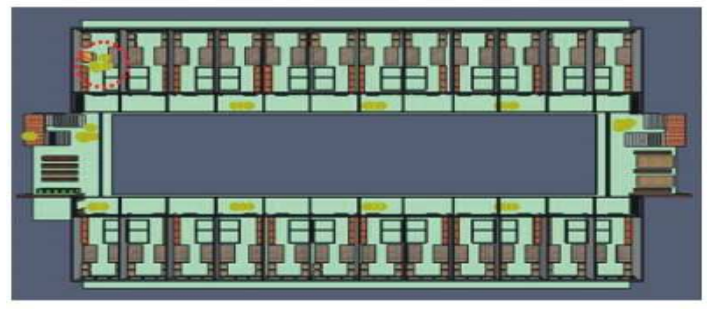

Fig. 4: Depicts the first floor of the building with the source of fire 
The product from the combustion is the toxic quantity that can be a cause of death to the evacuating person. In this research, only gases that make the evacuating person unconscious are investigated. Whereas the density ratio of NFPA (2002) or the Fraction Effective Dose (FED) is shown in Eq. 2:

$\mathrm{FED}_{\text {tot }}=\mathrm{FED}_{\mathrm{CO}_{2}} \times \mathrm{HV}_{\mathrm{CO}_{2}}+\mathrm{FED}_{\mathrm{O}_{2}}$

In addition, the ratio of $\mathrm{CO}$ that is harmful or can decrease the ability is shown in Eq. 3:

$\mathrm{FED}_{\mathrm{CO}}=4.607 \times 10^{-7}\left(\mathrm{C}_{\mathrm{CO}}\right)^{1.036} \times \mathrm{t}$

where, $\mathrm{C}_{\mathrm{CO}}$ is the percentage of density by volume of $\mathrm{CO}$.

The ratio of $\mathrm{O}_{2}$ that is harmful and is a cause of hypoxemia is shown in Eq. 4:

$$
\mathrm{FED}_{\mathrm{O}_{2}}=\frac{\mathrm{t}}{60 \exp \left[8.13-0.54\left(20.9-\mathrm{C}_{\mathrm{O}_{2}}\right)\right]}
$$

where, $\mathrm{C}_{\mathrm{O}_{2}}$ is the percentage of density by volume of $\mathrm{O}_{2}$.

The factor of $\mathrm{CO}_{2}$ that is a cause of suffocation is further shown in Eq. 5:

$$
\mathrm{HV}_{\mathrm{CO}_{2}}=\frac{\exp \left(0.1930 \mathrm{C}_{\mathrm{CO}_{2}}+2.004\right)}{7.1}
$$

where, $\mathrm{C}_{\mathrm{CO} 2}$ is the percentage of density by volume of $\mathrm{CO}_{2}$.

Table 1: Shows the conditions to select the size of fire (heat release rate) in the fire situation simulation by types of building

\begin{tabular}{ll}
\hline Types of buildings & Heat release rate $(\mathrm{kW})$ \\
\hline Airport and railway station & More than 7,000 \\
Department store and public buildings & 5,000 \\
Building hall or inner opened-space & More than 7,000 \\
Barrier part of railway station & 1,000 \\
\hline
\end{tabular}

Table 2: Shows the air temperature by the duration of evacuating people's endurance

\begin{tabular}{ll}
\hline Air temperature & Duration of evacuating people's endurance \\
\hline $60^{\circ} \mathrm{C}\left(140^{\circ} \mathrm{F}\right)$ & $2-3 \mathrm{~min}$ \\
$49^{\circ} \mathrm{C}\left(120^{\circ} \mathrm{F}\right)$ & Less than $6 \mathrm{~min}$ \\
\hline
\end{tabular}

Table 3: Shows the $\mathrm{CO}_{2}$ volume that the evacuating people can endure

\begin{tabular}{ll}
\hline $\mathrm{CO}_{2}$ & Duration of evacuating people's endurance \\
\hline$\geq 2,000 \mathrm{PPM}$ & $2-3 \mathrm{~min}$ \\
$1,500 \mathrm{PPM}$ & Less than $6 \mathrm{~min}$ \\
$800 \mathrm{PPM}$ & Less than $15 \mathrm{~min}$ \\
$50 \mathrm{PPM}$ & Residues from combustion \\
\hline
\end{tabular}

\section{RESULTS}

There are 4 experimentations in this research in which the fire situation in the student dormitory was simulated. The investigations have been made by comparing (1) the case of exit door expansion from 1-2 $\mathrm{m}$ and (2) the case of the smoke barrier with the size of 30 centimeters is additional installed. The purpose is to make the comparison for building modification and improvement as shown in Fig. 5 and 6.

In Table 4, the evacuation data for 4 cases are presented by the size of the exit and by the different types of fire barrier.

In Fig. 7-10, the $\mathrm{CO}_{2}$ volume comparisons among 4 types of stair passage are shown.
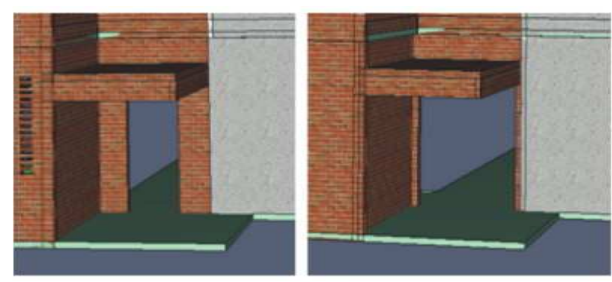

Fig. 5: Shows the exit door expansion from 1-2 $\mathrm{m}$

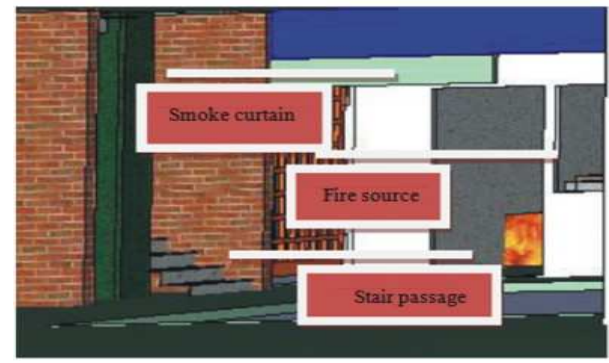

Fig. 6: Shows the location to install the fire barrier in front of stair passage of the first floor

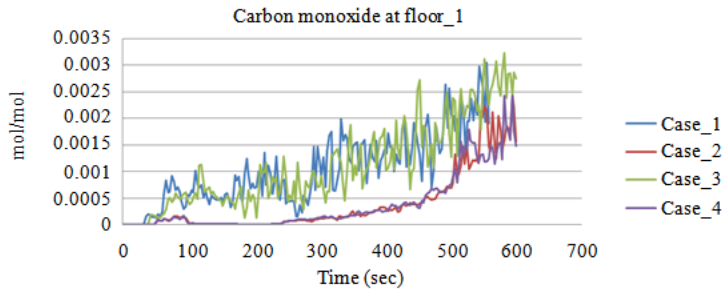

Fig. 7: Shows the CO volume for the first floor

Table 4: Shows the total time of evacuation from student dormitory

\begin{tabular}{llll}
\hline $\begin{array}{l}\text { Size of the } \\
\text { exit }(\mathrm{m})\end{array}$ & Fire barrier & $\begin{array}{l}\text { Evacuation } \\
\text { time }(\mathrm{sec})\end{array}$ & $\begin{array}{l}\text { Number of } \\
\text { dead (person) }\end{array}$ \\
\hline 1 & Uninstalled & 462 & - \\
1 & Installed & 463 & - \\
2 & Uninstalled & 278 & - \\
2 & Installed & 280 & - \\
\hline
\end{tabular}




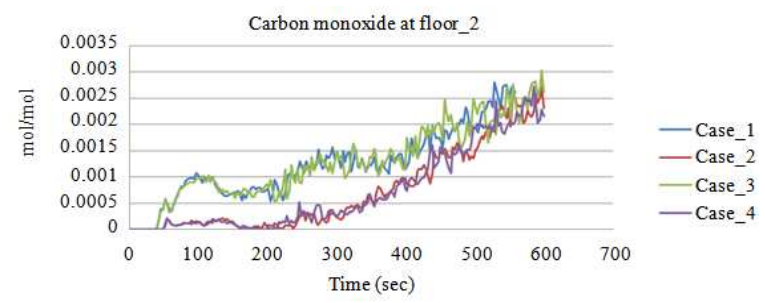

Fig. 8: Shows the CO volume for the second floor

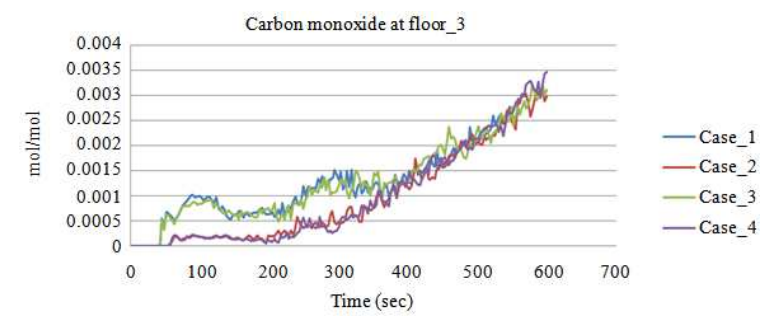

Fig. 9: Shows the CO volume for the third floor

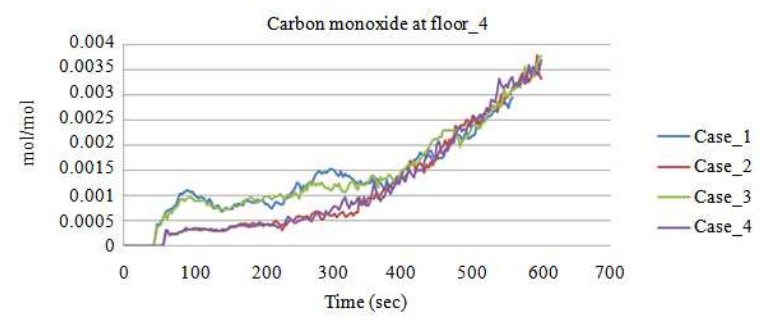

Fig. 10: Shows the CO volume for the fourth floor

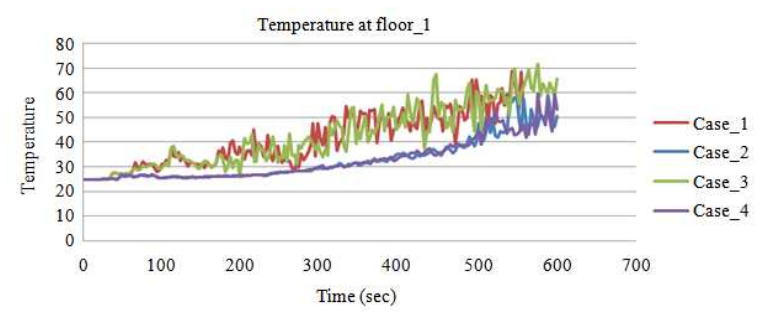

Fig. 11: Shows the graph of temperature of the first floor

From Fig. 7-10, the $\mathrm{CO}$ volume is measured by 4 types of stair passage. Because of the smoke barrier is not installed in the first case and the third case, the $\mathrm{CO}$ volume that can be detected is higher than the second case and the fourth case. The $\mathrm{CO}$ volume of the first floor is significantly differed from other floors. In this research, the temperature comparison is further done in which the results are shown in Fig. 11-14.

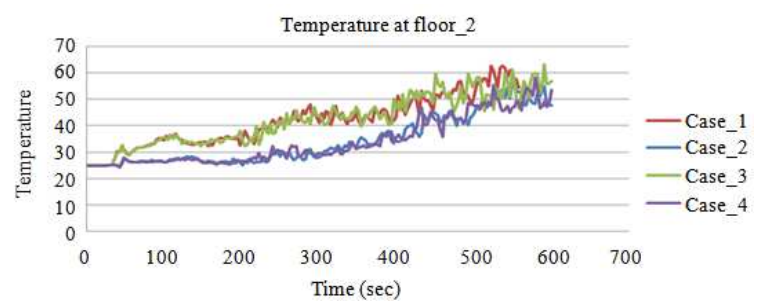

Fig. 12: Shows the graph of temperature of the second floor

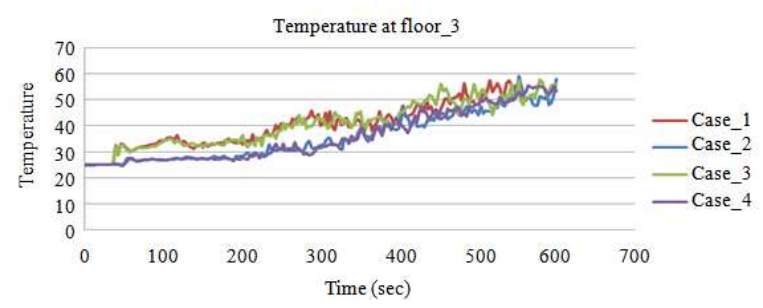

Fig. 13: Shows the graph of temperature of the third floor

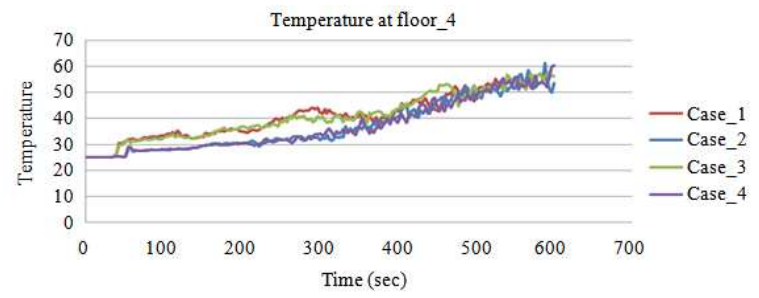

Fig. 14: Shows the graph of temperature of the fourth floor

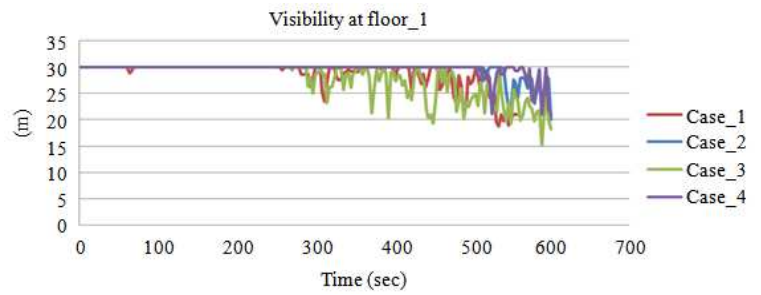

Fig. 15: Shows the visibility performance of the first floor

As shown in Fig. 11-14, the measured temperature in the stair passage of the first and the third case is increased with uncertain direction. The reason is the inlet smoke through the stair passage is no direction. The differentiation is found in the second case and the fourth case in which the smoke barrier is installed leading to less smoke and lower temperature.

The other experimentations of visibility performance are further investigated in this research. The results are shown in Fig. 15-18 for 4 case. 


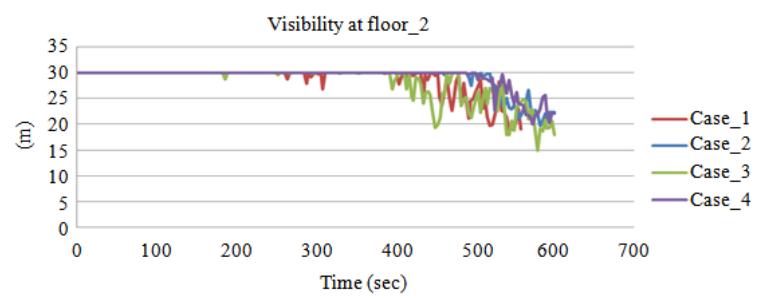

Fig. 16: Shows the visibility performance of the second floor

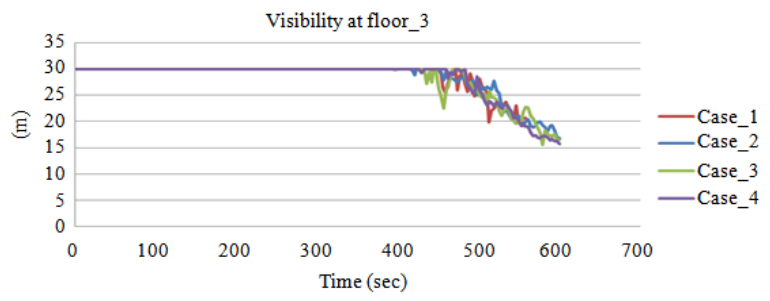

Fig. 17: Shows the visibility performance of the third floor

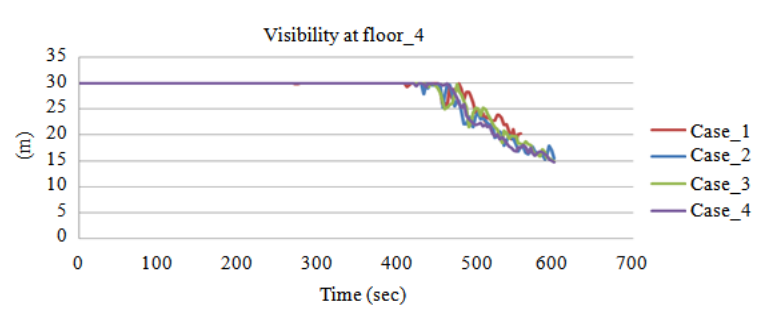

Fig. 18: Shows the visibility performance of the fourth floor

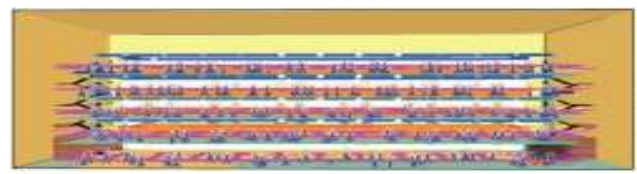

Fig. 19: Shows the evacuation status at $15 \mathrm{sec}$

From Fig. 15-18, the results can be seen that the visibility performance for all cases is rather fallen in the same level. The differentiation is found in the first floor and the second floor in that the visibility performance of the second case and the fourth case is better than the first case and the third case.

From Fig. 19-25, the evacuation of the user for the first case is shown by the last time duration of evacuating people for each floor of the building. The first case is the building that is always used without the exit improvement and without the smoke barrier installation before entering to the stair passage. Thus the first case uses more time of evacuation and has a risk of high smoke in the stair passage.

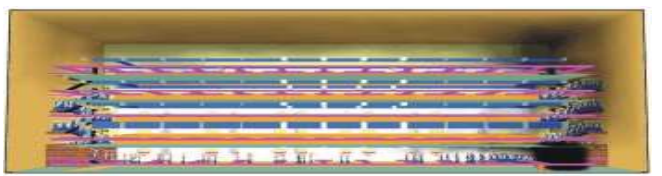

Fig. 20: Shows the evacuation status at $130 \mathrm{sec}$

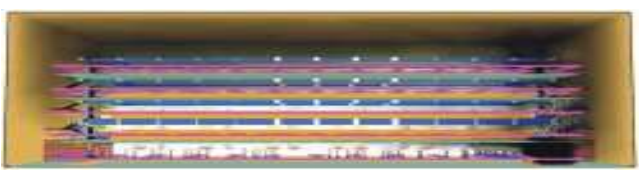

Fig. 21: Shows the evacuation status at $190 \mathrm{sec}$

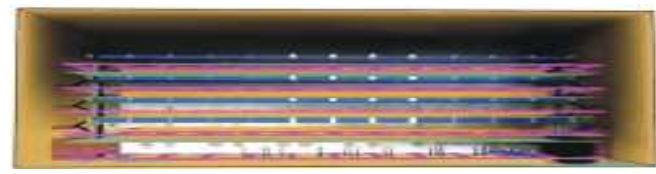

Fig. 22: Shows the evacuation status at $230 \mathrm{sec}$

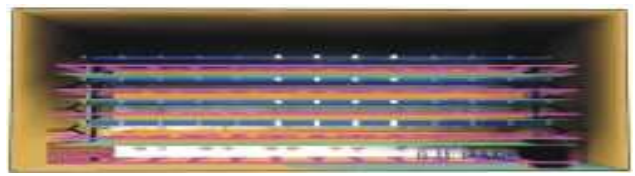

Fig. 23: Shows the evacuation status at $250 \mathrm{sec}$

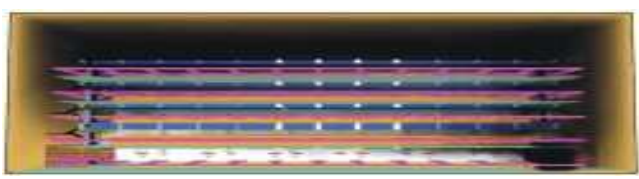

Fig. 24: Shows the evacuation status at $265 \mathrm{sec}$

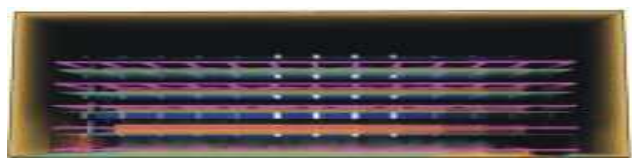

Fig. 25: Shows the evacuation status at $465 \mathrm{sec}$

From Fig. 19-25, the results of evacuation status after the people perceived the fire alarm signal are shown. From Fig. 19 at $15 \mathrm{sec}$, the people start evacuating from the room by running to the nearest exit, which has 2 exits. Because of large amount of people at each floor, the accumulating and waiting at the stair passage is occurred. From Fig. 23, all people can leave from the room around $250 \mathrm{sec}$ and can leave from the building around 460 as shown in Fig. 25. The waiting time at the in front of the building exit is approximately $210 \mathrm{sec}$. 


\section{DISCUSSION}

The evacuation from the student dormitory of the first case and the second case uses the similar evacuation time, however, the time is longer than the third case and the fourth case. The reason is the smaller size of the exit in which the evacuation time is longer.

The data collection is found that most of evacuating people equally select to use both of the stairs.

For all cases, the defined duration of evacuation time from each floor is found to have no casualties. The reason from the NFPA 130 standard is that the maximum temperature that the human can be handled is $60^{\circ} \mathrm{C}$. With this temperature, the human can stay for only a short time. In addition, the index of dead people is the Fraction Effective Dose (or FED) equals to 1, whereas the FED is the summation among the ratio of $\mathrm{CO}, \mathrm{CO}_{2}$ and $\mathrm{O}_{2}$. The data that can be obtained from the standard table are for fire source location and in front of the fire source room in which the location of fire escaping path has the temperature lower than $60^{\circ} \mathrm{C}$.

\section{CONCLUSION}

The result from the simulation program shows that there are no dead people from 4 cases. The reason is the characteristics of the building that is opened. So the smoke is not accumulated in the building leading to lower risk from smoke. The number of the stairs that has 2 paths provides the evacuating people selecting the safe path. However, the stair is not the fire exit, so the stair passage can be an obstacle for evacuation. This is because the smoke can be entered to the stair passage in case the fire close to the stair passage.

In addition, the result is shown that the size of the exit and the stair characteristics, which is not the fire stair, can have direct impact to the evacuating people. The reason is a large number of evacuating people, which is not suitable to the small door size. So, there is the accumulation and waiting at the exit. The stair in the building is not designed for the fire escaping purpose, thus there is a risk that a smoke can leak to the stair passage. This can harm the human life and can affect the evacuation. So, the stair improvement is required by installing the smoke barrier with 30 centimeter width and $2 \mathrm{~m}$ length. In addition, the door should expand from 1-2 $\mathrm{m}$ to increase the evacuation ability.

From experimentations to make the comparison for the improvement, it is shown that the door expansion can reduce the evacuation time from normal evacuation time at 450-250 sec after the door size is improved. In addition, the installation of smoke barrier in the beam that located before entering the stair passage can reduce the smoke quantity entering through the stair passage in case the fire source close to the stair passage. This improvement can reduce the smoke quantity, reduce the heat and reduce the $\mathrm{CO}$ in a large amount.

\section{ACKNOWLEDGMENT}

This research was funded by the Kasetsart University, Si Racha Campus on 2010.

\section{REFERENCES}

Jahn, W., G. Rein and J.L. Torero, 2011. Forecasting fire growth using an inverse zone modelling approach. Fire Safety J., 46: 81-88. DOI: 10.1016/j.firesaf.2010.10.001

Lin, C.J. and Y.K. Chuah, 2008. A study on long tunnel smoke extraction strategies by numerical simulation. Tunnel. Underground Space Technol., 23: 522-530. DOI: 10.1016/j.tust.2007.09.003

Ma, T.G. and J.G. Quintiere, 2003. Numerical simulation of axi-symmetric fire plumes: Accuracy and limitations. Fire Safety J., 38: 467-492. DOI: 10.1016/S0379-7112(02)00082-6

Majee, N.C. and A.B. Roy, 2010. Asymptotic behavior of an artificial neural network defined on multipartite directed graph. OnLine J. Biol. Sci., 10: 44-49. DOI: $10.3844 /$ ojbsci.2010.44.49

Merry, K., P. Bettinger and J. Hepinstall, 2009. Physical and biological responses of forests to tropical cyclones affecting the united states atlantic ocean and gulf of Mexico coasts. Am. J. Environ. Sci., 5: 16-32. DOI: 10.3844/ajessp.2009.16.32

Momani, N.M., 2010. Business continuity planning: Are we prepared for future disasters. Am. J. Econ. Bus. Admin., 2: 272-279. DOI: 10.3844/ajebasp.2010.272.279

Mouilleau, Y. and A. Champassith, 2009. CFD simulations of atmospheric gas dispersion using the Fire Dynamics Simulator (FDS). J. Loss Prev. Proc. Indus., 22: 316-323. DOI: 10.1016/j.jlp.2008.11.009

NFPA, 2002. SFPE Handbook of Fire Protection Engineering. 3rd Edn., National Fire Protection Association, Boston, Massachusetts, ISBN: 0877654514.

Qin, T.X., Y.C. Guo, C.K. Chan and W.Y. Lin, 2009. Numerical simulation of the spread of smoke in an atrium under fire scenario. Build. Environ., 44: 5665. DOI: 10.1016/j.buildenv.2008.01.014 
Roh, J.S., H.S. Ryou, W.H. Park and Y.J. Jang, 2009. CFD simulation and assessment of life safety in a subway train fire. Tunnelling Underground Space Technol., 24 : 447-453. $\quad$ DOI: 10.1016/j.tust.2008.12.003

Xin, Y., J.P. Gore, K.B. McGrattan, R.G. Rehm and H.R. Baum, 2005. Fire dynamics simulation of a turbulent buoyant flame using a mixture-fractionbased combustion model. Combustion Flame, 141: 329-335.

DOI: 10.1016/j.combustflame.2004.07.001

Yang, P., X. Tan and W. Xin, 2011. Experimental study and numerical simulation for a storehouse fire accident. Build. Environ., 46: 1445-1459. DOI: 10.1016/j.buildenv.2011.01.012
Zahim, S.M., M. Norainon, J.M. Shawal and R.I.R.M. Taufika, 2009. Iterative numerical method of gate turn-off thyristor: Comparative study between $\mathrm{Si}$ and SiC. Am. J. Eng. Applied Sci., 2: 446-450. DOI: 10.3844/ajeassp.2009.446.450

Zhang, X.G., Y.C. Guo, C.K. Chan and W.Y. Lin, 2007. Numerical simulations on fire spread and smoke movement in an underground car park. Build. Environ., 42: 3466-3475. DOI: 10.1016/j.buildenv.2006.11.002

Zhi-Xiang, X., Z. Xiao-Fang, S. Hua and G. Wen-Li, 2011. Applied research of performance-based fire protection design in a large building. Proc. Eng., 11: 566-574. DOI: 10.1016/j.proeng.2011.04.697 